\title{
Resistance exercise performed with repetitions until failure affects nocturnal blood pressure decreases in hypertensive women
}

\author{
Exercício de força realizado com repetições até à falha concêntrica altera a \\ redução noturna da pressão arterial em mulheres hipertensas
}

\author{
Marilia de Almeida Correia ${ }^{1}$, Aluísio Henrique Rodrigues Andrade Lima ${ }^{2}$, Crivaldo Gomes \\ Cardoso-Junior ${ }^{3}$, Anderson José Melo Rodrigues-da-Silva ${ }^{1}$, Jacilene Guedes Oliveira ${ }^{1}$, Bruno \\ Remígio Cavalcante ${ }^{1}$, Bruna Cadengue Coelho Souza ${ }^{1}$, Edson Magno Macedo-Junior ${ }^{4}$, Dário \\ Celestino Sobral-Filho ${ }^{4}$, Raphael Mendes Ritti-Dias ${ }^{1 *}$
}

ARTIGO ORIGINAL | ORIGINAL ARTICLE

\begin{abstract}
Studies have shown that resistance exercise reduces 24-hour blood pressure to levels below resting values, although this is not a universal finding. The number of repetitions has been shown to influence this response. Thus, the aim of the study was to analyze the effects of resistance exercise performed until failure (UF) on 24-hour blood pressure in hypertensive women. Thirteen hypertensive women underwent three experimental sessions in random order: UF, resistance exercise with repetitions before concentric failure (BF) and control (C). Prior to and up to 24 hours after the sessions, cardiovascular variables, as well as the nocturnal fall in blood pressure, the morning surge, and the presence or absence of a blood pressure dip pattern were established using an ambulatory blood pressure monitor. In both wakefulness and sleep there was no significant difference among the three groups. However, after UF and C fewer patients presented a dip in blood pressure ( $46 \%$ and $38 \%$, respectively) compared BF $(77 \%), p=0.047$. In conclusion, the UF attenuated blood pressure dips at night in hypertensive patients.

Key words: blood pressure, hypertension, muscle failure, resistance exercise.
\end{abstract}

RESUMO

Estudos vêm demonstrando que o exercício de força reduz a pressão arterial para níveis abaixo dos valores de repouso, entretanto este não é um achado universal. O número de repetições do exercício parece influenciar essas respostas. Assim, o objetivo do estudo foi analisar os efeitos do exercício de força realizado com repetições até a falha concêntrica sobre a pressão arterial de 24 horas em mulheres hipertensas. Treze mulheres hipertensas foram submetidas a três sessões experimentais em ordem aleatória: controle (C), exercício de força até a falha concêntrica $(\mathrm{FC})$ e exercício de força com repetições até a redução da cadência (RC). Antes e 24 horas após as sessões as variáveis cardiovasculares - descenso noturno, ascensão matutina e presença ou não de padrão dipper - foram avaliadas por meio de monitorização ambulatorial da pressão arterial. Nos períodos diurno e noturno, não houve diferença significativa entre os três grupos. Entretanto, após FC e C, menos sujeitos apresentaram padrão dipper da pressão arterial (46\% e 38\%, respectivamente) do que quando comparado aos grupos RC (77\%), $\mathrm{p}=0.047$. Como conclusão, o FC atenuou a o padrão dipper da pressão arterial noturna em mulheres hipertensas.

Palavras-chave: pressão arterial, hipertensão, fadiga muscular, exercício de força.

Manuscript received August 20 ${ }^{\text {th }}, 2014$; Accepted October 26 ${ }^{\text {th }}, 2014$

${ }^{1}$ Associated Graduate Program in Physical Education UPE/UFPB, University of Pernambuco, Recife, Brazil

${ }^{2}$ Exercise Hemodynamic Laboratory, School of Physical Education and Sport, University of São Paulo, Brazil

${ }^{3}$ Center of Physical Education and Sport, State University of Londrina, Brazil

${ }^{4}$ Procape University Hospital, University of Pernambuco, Brasil

* Corresponding author. Avenida Albert Einstein, 627/701, Morumbi. São Paulo, SP. Brazil. ZIP-code: 05652900. Phone: (+5511) 21511233. E-mail: raphaelritti@gmail.com 


\section{INTRODUCTION}

Hypertension affects $30-45 \%$ of adults around the world (Mancia et al., 2013) and is an important cardiovascular risk factor (Cornelissen, Fagard, Coeckelberghs, \& Vanhees, 2011; Cornelissen \& Smart, 2013; Mancia et al., 2013) directly related to cardiovascular morbidity and mortality (Cornelissen et al., 2011). Lifestyle changes are the first line of therapy for hypertensive patients and exercise programs have been widely encouraged (Mancia et al., 2013).

Resistance exercise has been recommended as part of the therapeutic approach in patients with hypertension (Pescatello et al., 2004). Studies have shown that resistance exercise reduces blood pressure (BP) to levels below resting values (Melo, Alencar Filho, Tinucci, Mion, \& Forjaz, 2006; Mota et al., 2009), although this is not a universal finding (Focht \& Koltyn, 1999; Roltsch, Mendez, Wilund, \& Hagberg, 2001). The different resistance exercise protocols used by various studies may explain these controversial findings, since variables such as exercised muscle mass and number of repetitions have been shown to influence post-exercise BP responses (Mediano, Paravidino, Simão, Pontes, \& Polito, 2005; Polito \& Farinatti, 2009). However, whether other resistance training variables influence cardiovascular parameters after resistance exercise remains unclear.

The Brazilian Guidelines on Hypertension (2010) recommend that hypertensive patients should avoid resistance exercise with repetitions until concentric failure (UF) in order to curb increases in BP during exercise. However a study observed that in normotensive adult women, UF resulted in a drop in BP on awakening, suggesting that this prescription may carry postexercise cardiovascular benefits for adult women (De Souza et al., 2013). However, given that hypertension, in combination with the use of anti-hypertensive medication, affects postexercise BP responses (Hermida, Ayala, Mojón, \& Fernández, 2010), it still unclear whether similar responses are to be found in hypertensive women.

The aim of this study was thus to analyze the effect of UF on 24-hour cardiovascular parameters in hypertensive women.

Subjects

Hypertensive women were recruited from universities and local communities. Patients with hypertension were included if they: (a) had a medical diagnosis of hypertension; (b) were aged $>30$ years; (c) were women; (d) were not smokers, obese (body mass index $<30.0 \mathrm{~kg} / \mathrm{m} 2$ ) or diabetic (d) were free of coronary artery disease or arrhythmias, and; (e) were not using antihypertensive medications that affect heart rate ( $\beta$-blockers and non-dihydropyridine calcium channel blockers).

Screening included body mass and height measurements to identify obesity and a maximal exercise test on a treadmill using the Bruce protocol (Eston \& Reilly, 2013) to identify coronary heart disease or severe arrhythmias. A medical history and a list of current medication were also obtained in order to identify diabetes and other cardiovascular diseases. Thirteen patients met the inclusion criteria. None of them were athletes or involved in systematic sports training. Before enrollment in the study, all patients provided written consent. The procedures used in this study were approved by the Institutional Review Board of the University.

\section{Procedures}

The study comprised eight sessions of adaptation to the resistance exercises, two sessions of 8-12RM to determine the loads for experimental sessions, and three experimental sessions. In the case of the experimental sessions, cardiovascular parameters were obtained prior to and up to 24 hours after the intervention.

\section{Adaptation sessions}

Patients underwent eight adaptation sessions for familiarization with the rating of perceived scales and with the cadence of resistance exercise using the metronome. These sessions were performed twice a week and also aimed to help patients improve their muscle fitness to be capable to complete the entire session of UF. The adaptation sessions consisted of nine exercises - 
$150 \mid$ MA Correia, AHRA Lima, CG Cardoso-Junior, AJM Rodrigues-da-Silva, JG Oliveira, BR Cavalcante, BCC Souza, EM Macedo-Junior, DC Sobral-Filho, RM Ritti-Dias

lat pulldown, knee extension, bench press, knee flexion, seated row, hip adduction, triceps pulley, unilateral hip flexion and biceps curl - each performed in one set of 10 repetitions with an intensity between 5 and 7 on the OMNI Resistance Exercise Scale (Gearhart, Lagally, Riechman, Andrews, \& Robertson, 2009; Robertson et al., 2003). All exercises were performed at a cadence of $1 \mathrm{sec} / 1 \mathrm{sec}$ for concentric and eccentric activities, as measured using a metronome.

The instructions for rating perceived exertion defined perceived exertion as the subjective intensity of effort, strain, discomfort, and/or fatigue experienced during the resistance exercise in the active muscle. The instructions also explained the nature and use of the OMNI scale differentiated ratings as well as how to use the low and high numerical categories as scale anchor points (Gearhart et al., 2001). The scale anchoring procedure provided the patient with an understanding of the range of sensations that correspond to the low and high rating categories. The OMNI-RES scale ranged from 0 to 10 , where 0 represents maximal rest (i.e., a seated position) and 10 represents perception above a point that patients could report during the resistance exercise.

\section{8-12 RM evaluation}

Two days after the last adaptation session, maximal dynamic strength was evaluated using the 8-12 repetition maximal (RM) test for the nine exercises previously described. After a warm-up set (10 repetitions) with approximately $50 \%$ of the load used in the first attempt, patients had two attempts to identify the 8-12RM load. In the first attempt, two researchers subjectively determined the load that would be used. In the second attempt, the load was defined based on the performance in the previous attempt. If the patient was able to complete more than 12 repetitions in the first attempt, the load in the second attempt was increased. If the patient was not able to complete eight repetitions, the load for the next attempt was decreased. The rest period between each attempt was 10 minutes. If the loads were not determined after two attempts, a new test session was scheduled 48 hours later. The $8-12 \mathrm{RM}$ was recorded as the weight that the patient was able to reach between 8-12 repetitions.

\section{Experimental sessions}

The patients underwent three experimental sessions: UF, resistance exercises before concentric failure (BF) and control (C). The order of the sessions was randomized. The sessions were conducted in the morning and the interval between them was at least three days. Prior to experimental sessions, patients were instructed to avoid physical exercise and ingestion of alcohol or caffeine, and to maintain their regular medication use.

In each of the three experimental sessions, patients rested in a supine position for 20 minutes in a quiet temperature-controlled room. After the first ten minutes of rest, baseline BP and heart rate were measured four times, with one minute of interval between measurements, using an ambulatory BP monitor (Dynamapa, Cardios, Brazil), placed on the non-dominant arm. After resting measurements, the equipment was disconnected and the patients began the experimental session.

In the $\mathrm{C}$ session, patients remained seated in the resistance exercise room, while in UF session, they performed the concentric exercises until failure, characterized as inability to continue the movement with the load. In the BF session, patients performed resistance exercises before concentric failure, characterized as a reduction in pace. The reduction in pace was determined by one evaluator who subjectively identified the slowed pace and requested that the patient desist. In all experimental sessions, the metronome was used to standardize the pace of muscle action (1 sec concentric / $1 \mathrm{sec}$ eccentric). In the BF and UF sessions, the rest interval between exercises was 2 min and before each exercise a warm up set of 10 repetitions with $25 \%$ of $8-12 \mathrm{RM}$ was performed.

After the interventions, patients returned to the laboratory to put on the ambulatory BP monitor, on the same arm as the pre experimental procedures, in order to assess 
cardiovascular responses every 15 minutes. Additionally, the pedometer (DigiWalker SW700 , Japan) was placed on one belt attached to waist to access physical activity during daily activities over a 24-hour period. The patients were asked to keep the ambulatory BP monitor equipment on all day and to remove the pedometer only to sleep.

\section{Ambulatory blood pressure variables}

Cardiovascular measurements over 24 hours (BP and heart rate), including waking and sleeping periods were calculated. The mean value of every hour was calculated as also the average of all, defining as mean BP 24 hours. The nocturnal BP fall was calculated in absolute terms (mean waking - mean sleeping BP), which was obtained by the mean of the values reported in the period that the patients were awake and sleeping, respectively. The patients were deemed to have experienced a dip if there was a normal nocturnal systolic BP fall of $\geq 10 \%$. The morning surge was calculated as the difference between the mean BP during the last two hours of sleep and that of the first two hours after waking.

\section{Statistical analysis}

The Gaussian distribution and the homogeneity of variance of the data were analyzed using the Shapiro-Wilk and Levene tests and one-way ANOVA was used to compare the baseline values (systolic BP, diastolic BP, mean $\mathrm{BP}$ and heart rate) among sessions (C, UF and $\mathrm{BF}$ ). Changes in cardiovascular variables (BP and heart rate) after the interventions were investigated, using two-way ANOVA for repeated measures, establishing sessions (C, UF and $\mathrm{BF}$ ) and time (pre and post-intervention) as the main factors. Cardiovascular variables obtained from the ambulatory BP monitor (BP, heart rate and rate pressure product during 24 hours, waking, sleeping and the morning BP surge) were compared among the three groups using one-way ANOVA for repeated measures. When necessary, post hoc comparisons were carried out using the Newman-Keuls test. To determine the proportion of patients with or without dips after the interventions, the chisquare and Fisher's exact test were used. For all analyses, $\mathrm{p}<0.05$ was taken to be statistically significant. Data are presented as mean \pm standard deviation.

\section{RESULTS}

The characteristics of the sample are presented in Table 1. The patients were in average overweight and had controlled BP. All patients were using antihypertensive medication and the most commonly used drugs were inhibitors of the angiotensin-converting enzyme.

Table 1

General characteristics of the patients $(n=13)$

\begin{tabular}{lc}
\hline Variables & Values \\
\hline Age (years) & $53 \pm 3$ \\
Weight $(\mathrm{kg})$ & $66 \pm 2$ \\
Height $(\mathrm{m})$ & $1.60 \pm 0.01$ \\
Body mass index $\left(\mathrm{kg} / \mathrm{m}^{2}\right)$ & $26 \pm 1$ \\
Waist circumference (cm) & $86 \pm 3$ \\
Hip circumference (cm) & $101 \pm 2$ \\
Waist/hip ratio & $0.90 \pm 0.02$ \\
Heart rate (bpm) & $82 \pm 3$ \\
Systolic blood pressure (mmHg) & $129 \pm 3$ \\
Diastolic blood pressure (mmHg) & $79 \pm 3$ \\
\multicolumn{1}{c}{ Medications } & \\
Inhibitors of angiotensin-converting & 46.0 \\
enzyme (\%) & 38.5 \\
Angiotensin receptor antagonist (\%) & 30.7 \\
Diuretic (\%) &
\end{tabular}

Pre-intervention cardiovascular variables were similar for all sessions ( $p>0.05)$. Figure 1 shows the responses of systolic BP, diastolic BP and heart rate before and hour-to-hour after experimental sessions.

No significant differences were observed among the three experimental sessions in cardiovascular variables during the 24 hours after the interventions ( $p>0.05)$. 
152 | MA Correia, AHRA Lima, CG Cardoso-Junior, AJM Rodrigues-da-Silva, JG Oliveira, BR Cavalcante, BCC Souza, EM Macedo-Junior, DC Sobral-Filho, RM Ritti-Dias
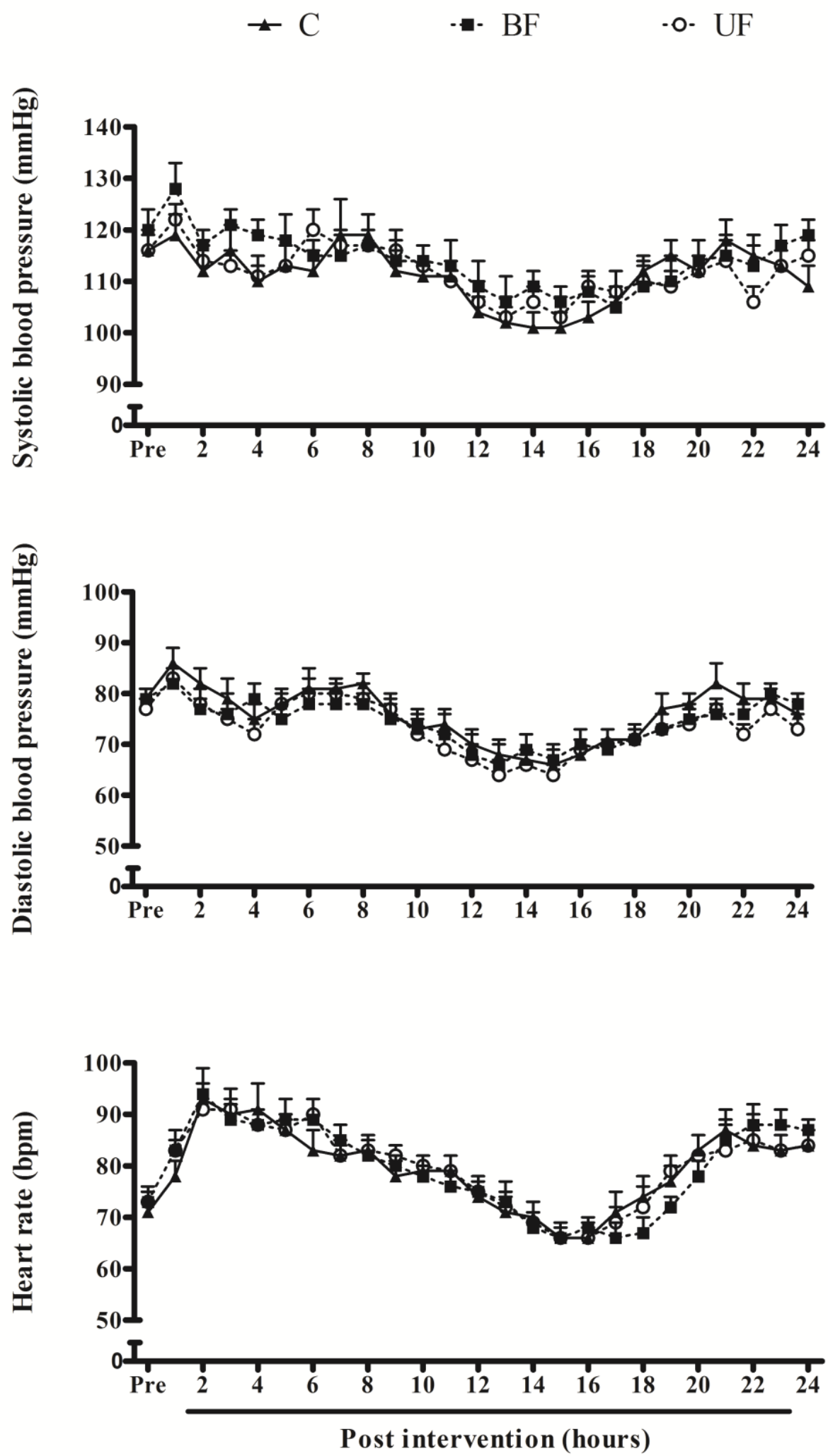

Figure 1. Systolic blood pressure, diastolic blood pressure and heart rate measured before and after interventions. Control (C: triangles), resistance exercise before concentric failure (BF: squares) and resistance exercise performed until concentric failure (UF: circles). 
Table 2 shows BP values and separately for 24-hour period, periods of waking and sleep, as well as the nocturnal BP dip and morning surge for the three groups.

Table 2

Cardiovascular variables measured after control (C), resistance exercise before concentric failure (BF) and resistance exercise until concentric failure (UF).

\begin{tabular}{|c|c|c|c|c|}
\hline Variables & $\mathrm{C}$ & $\mathrm{BF}$ & UF & $p$ \\
\hline \multicolumn{5}{|l|}{24 hours } \\
\hline Systolic blood pressure $(\mathrm{mmHg})$ & $111 \pm 2$ & $114 \pm 2$ & $112 \pm 2$ & 0.42 \\
\hline Diastolic blood pressure ( $\mathrm{mmHg}$ ) & $76 \pm 1$ & $75 \pm 2$ & $73 \pm 2$ & 0.12 \\
\hline Mean blood pressure (mmHg) & $90 \pm 2$ & $92 \pm 2$ & $89 \pm 2$ & 0.54 \\
\hline Heart rate (bpm) & $79 \pm 2$ & $80 \pm 2$ & $80 \pm 2$ & 0.97 \\
\hline \multicolumn{5}{|l|}{ Awake } \\
\hline Systolic blood pressure $(\mathrm{mmHg})$ & $115 \pm 3$ & $118 \pm 2$ & $115 \pm 2$ & 0.27 \\
\hline Diastolic blood pressure (mmHg) & $79 \pm 2$ & $78 \pm 2$ & $77 \pm 2$ & 0.31 \\
\hline Mean blood pressure $(\mathrm{mmHg})$ & $93 \pm 3$ & $96 \pm 2$ & $93 \pm 2$ & 0.39 \\
\hline Heart rate (bpm) & $84 \pm 2$ & $85 \pm 2$ & $85 \pm 2$ & 0.76 \\
\hline \multicolumn{5}{|l|}{ Asleep } \\
\hline Systolic blood pressure $(\mathrm{mmHg})$ & $104 \pm 2$ & $104 \pm 3$ & $105 \pm 3$ & 0.95 \\
\hline Diastolic blood pressure (mmHg) & $69 \pm 2$ & $66 \pm 2$ & $66 \pm 2$ & 0.20 \\
\hline Mean blood pressure (mmHg) & $83 \pm 3$ & $83 \pm 2$ & $82 \pm 3$ & 0.94 \\
\hline Heart rate $(\mathrm{bpm})$ & $69 \pm 2$ & $68 \pm 2$ & $68 \pm 2$ & 0.33 \\
\hline \multicolumn{5}{|c|}{ Nocturnal blood pressure fall } \\
\hline Systolic blood pressure (\%) & $8 \pm 3$ & $12 \pm 1$ & $9 \pm 2$ & 0.38 \\
\hline Diastolic blood pressure (\%) & $13 \pm 3$ & $16 \pm 1$ & $15 \pm 2$ & 0.64 \\
\hline Morning Surge & & & & \\
\hline
\end{tabular}

Data are presented as mean \pm standard deviation. ${ }^{*}$ Different of the UF.



Figure 2. Proportion of dipper and non-dipper patients after interventions. Control (C), resistance exercise performed before concentric failure $(\mathrm{BF})$ and resistance exercise performed until concentric failure sessions (UF). \# Difference compared to UF and C. 
154 | MA Correia, AHRA Lima, CG Cardoso-Junior, AJM Rodrigues-da-Silva, JG Oliveira, BR Cavalcante, BCC Souza, EM Macedo-Junior, DC Sobral-Filho, RM Ritti-Dias

Systolic and diastolic BP and heart rate were similar for the three experimental sessions over a period of 24 hours, and during periods of wakefulness and sleep. The morning BP surge was greater after the BF session compared to the UF session $(p=0.029)$.

Figure 2 shows the proportion of patients with a dip in BP for each group. The proportion of patients experiencing a dip was higher after the $\mathrm{BF}$ session compared to the other sessions ( $p$ $=0.047$ ).

Figure 3 show the individual responses of nocturnal blood pressure fall and morning surge to experimental sessions corrected by the control session. It is possible to observe that nine patients had greater fall and greater increases in morning surge after BF.

The number of steps over the period that the patients were using ambulatory BP monitor was similar for all sessions (C: $7326 \pm 930$ steps, BF: $8063 \pm 1304$ steps; UF: $8134 \pm 1158$ steps, $p>$ $0.05)$, indicating that the results observed were not influenced by the amount of physical activity performed after the experimental sessions.


Figure 3. Individual responses to resistance exercise performed until concentric failure (UF) and resistance exercise performed before concentric failure (BF) corrected by control session

\section{DISCUSSION}

The results of the present study indicate (i) that BP and heart rate responses over a 24-hour period and during periods of wakefulness and sleep may be similar after UF, BF and C sessions; and (ii) that UF may reduce the nocturnal dip in BP compared to BF.

Unlike previous studies that observed a prolonged decrease in the $\mathrm{BP}$ in hypertensive individuals (Melo et al., 2006; Mota et al., 2009), the present study did not find any change in BP after resistance exercise. A number of factors may explain this. The patients' levels of BP prior to the intervention were well controlled and the increase in postexercise hypotension tends to be greater in subjects with higher resting BP (Queiroz, Gagliardi, Forjaz, \& Rezk, 2009). In fact, the mean systolic BP before the experimental sessions ranged from 116 to $120 \mathrm{mmHg}$ and approximately $92 \%$ of the patients had BP levels below 140/90 mmHg. Furthermore, studies have shown that post-exercise BP reduction is greater in physically inactive subjects and in subjects that are not practicing resistance exercises (Costa, Gerage, Gonçalves, Pina, \& Polito, 2010; Gerage et al., 2007; Moraes et al., 2007). It is therefore possible that the adaptation period that the patients underwent prior to the experimental sessions may have lessened the post-exercise BP reduction observed in the present study.

Two previous studies found decreases in $\mathrm{BP}$ during sleep in normotensive subjects that performed a single session of resistance exercise (Bermudes, Vassallo, Vasquez, \& Lima, 2004; Prista et al., 2013), although this is not a universal finding (De Souza et al., 2013). Interestingly, although in the present study we did not find any significant changes in BP 
during sleep, there was a decrease in the number of patients who experienced a dip (defined as a decrease in BP of $>10 \%$ ) after UF compared to BF. This dip in systolic BP has been associated with a reduction in the risk for cardiovascular events (Cornelissen et al., 2011), suggesting that UF may increase cardiovascular risk in hypertensive patients. The mechanisms responsible for the non-dip response after UF are not clear. It is possible that undertaking resistance exercise until fatigue may generate micro-lesions in the skeletal muscle (Dolezal, Potteiger, Jacobsen, \& Benedict, 2000; Medrano, 2010) increasing the levels of inflammatory markers (Medrano, 2010) and thus leading to increases in BP levels. Another explanation is related to sympathetic activation. A previous study found that resistance exercise performed UF reduced cardiac parasympathetic modulation for 24 hours, including during sleep (De Souza et al., 2013). UF may have also increased sympathetic nerve activity during sleep, thereby curbing nocturnal reductions in BP. These hypotheses require further investigation.

The morning surge has been associated with a higher risk of ischemic and hemorrhagic stroke (Kario et al., 2003), although the acute effects of resistance exercise on this variable have been poorly described. A previous study identified that UF attenuated BP increases upon waking (De Souza et al., 2013), although the present study found no changes in the morning surge after a UF session. Moreover, in the present study, the morning surge was more pronounced after the BF session, which may suggest that this session may increase cardiovascular risk in the morning. Nevertheless, it is worth noting that the highest morning surge value observed after a BF session was $42 \mathrm{mmHg}$, and $85 \%$ of the patients did not experience a surge of more than $27 \mathrm{mmHg}$. A previous study observed that a morning surge of more than $55 \mathrm{mmHg}$ is associated with an increase in cardiovascular risk, but it remains unclear whether the increases observed in this study are clinically significant (Kario et al., 2003).
The analysis of individual responses corrected by the control session showed that after BF nine patients had greater nocturnal blood pressure fall than UF. The same pattern was observed with the morning surge where nine patients had greater increases after BF compared to UF. This individual variation indicates that the BP responses after resistance exercise may be different between patients, which should be investigated. These data suggest that patients who had greater nocturnal fall also had greater morning surge.

The Brazilian Guidelines on Hypertension (2010) include in their recommendations that hypertensive patients should not perform UF, in order to avoid the pronounced increases in systolic BP that occur during resistance exercise. In support, a previous study found that interruption of resistance exercise at this point can reduce increases in systolic BP during resistance exercise by $25 \mathrm{mmHg}$ compared to UF (Gomides, Nery, Júnior, Tinucci, \& Forjaz, 2007). The present study provides an additional finding that in most of patients BF also brings cardiovascular benefits, since, after this session, patients were more likely to experience a significant dip in nocturnal BP compared to UF and C. Taken together these results indicate that avoiding fatigue during resistance exercise may be a useful way for hypertensive patients to prevent an increase in cardiovascular risk. It should be noted that the duration of each set of exercises in the $\mathrm{BF}$ session was determined by an evaluator who identified a change in the pace. A previous study showed that such a procedure has a good inter-rater reliability (Oliveira et al., 2013). From a practical point of view, therefore, the procedures employed in the present study can be used by clinicians and trainers supervising hypertensive patients during resistance training programs.

\section{CONCLUSION}

In conclusion, UF mitigated nocturnal BP decreases at night in selected hypertensive patients suggesting that this type of exercise may increase cardiovascular risk in these 
156 | MA Correia, AHRA Lima, CG Cardoso-Junior, AJM Rodrigues-da-Silva, JG Oliveira, BR Cavalcante, BCC Souza, EM Macedo-Junior, DC Sobral-Filho, RM Ritti-Dias

patients. In addition, individual analysis showed that patients should respond differently to resistance exercise's types. This finding should be borne in mind when prescribing resistance exercise for hypertensive patients.

\section{Acknowledgments:}

Nothing to declare.

\section{Conflicts of Interest:}

Nothing to declare.

\section{Funding:}

Financial support was provided by Coordenação de Aperfeiçoamento de Pessoal de Nível Superior (CAPES) and Pronto Socorro Cardiológico de Pernambuco (PROCAPE).

\section{REFERENCES}

Bermudes, A. M. L. de M., Vassallo, D. V., Vasquez, E. C., \& Lima, E. G. (2004). Ambulatory blood pressure monitoring in normotensive individuals undergoing two single exercise sessions: resistive exercise training and aerobic exercise training. Arquivos Brasileiros De Cardiologia, 82(1), 65-71, 57-64.

Cornelissen, V. A., Fagard, R. H., Coeckelberghs, E., \& Vanhees, L. (2011). Impact of resistance training on blood pressure and other cardiovascular risk factors: a meta-analysis of randomized, controlled trials. Hypertension, 58(5), 950-958. http://doi.org/10.1161/HYPERTENSIONAH A.111.177071

Cornelissen, V. A., \& Smart, N. A. (2013). Exercise training for blood pressure: a systematic review and meta-analysis. Journal of the American Heart Association, 2(1), e004473. http://doi.org/10.1161/JAHA.112.004473

Costa, J. B. Y., Gerage, A. M., Gonçalves, C. G. S., Pina, F. L. C., \& Polito, M. D. (2010). Influence of the training status on the blood pressure behavior after a resistance training session in hypertensive older females. Revista Brasileira de Medicina do Esporte, 16(2), 103-106. http://doi.org/10.1590/S151786922010000200005

De Souza, J. C., Tibana, R. A., Cavaglieri, C. R., Vieira, D. C. L., De Sousa, N. M. F., Mendes, F.
A. D. S., ... Prestes, J. (2013). Resistance exercise leading to failure versus not to failure: effects on cardiovascular control. $B M C$ Cardiovascular Disorders, 13, 105. http://doi.org/10.1186/1471-2261-13-105

Dolezal, B. A., Potteiger, J. A., Jacobsen, D. J., \& Benedict, S. H. (2000). Muscle damage and resting metabolic rate after acute resistance exercise with an eccentric overload. Medicine and Science in Sports and Exercise, 32(7), 1202-1207.

Eston, R., \& Reilly, T. (2013). Kinanthropometry and Exercise Physiology Laboratory Manual: Tests, Procedures and Data: Volume Two: Physiology. New York: Routledge.

Focht, B. C., \& Koltyn, K. F. (1999). Influence of resistance exercise of different intensities on state anxiety and blood pressure. Medicine and Science in Sports and Exercise, 31(3), 456-463.

Gearhart, R. F., Goss, F. L., Lagally, K. M., Jakicic, J. M., Gallagher, J., \& Robertson, R. J. (2001). Standardized scaling procedures for rating perceived exertion during resistance exercise. Journal of Strength and Conditioning Research, 15(3), 320-325.

Gearhart, R. F., Lagally, K. M., Riechman, S. E., Andrews, R. D., \& Robertson, R. J. (2009). Strength tracking using the OMNI resistance exercise scale in older men and women. Journal of Strength and Conditioning Research, 23(3), 1011-1015. http://doi.org/10.1519/JSC.0b013e3181a2ec4 1

Gerage, A. M., Cyrino, E. S., Schiavoni, D., Nakamura, F. Y., Ronque, E. R. V., Gurjão, A. L. D., \& Gobbi, S. (2007). Effect of 16-week weight training over blood pressure in normotensive and non-trained women. Revista Brasileira de Medicina do Esporte, 13(6), 361365. 86922007000600001

Gomides, R. S., Nery, S. S., Júnior, D. S., Tinucci, T., \& Forjaz, C. L. M. (2007). Pressão arterial durante o exercício resistido de diferentes intensidades em indivíduos hipertensos. Coleção Pesquisa em Educação Física, 6(1), 435-442.

Hermida, R. C., Ayala, D. E., Mojón, A., \& Fernández, J. R. (2010). Influence of circadian time of hypertension treatment on cardiovascular risk: results of the MAPEC study. Chronobiology International, 27(8), 1629-1651.

http://doi.org/10.3109/07420528.2010.51023 0

Kario, K., Pickering, T. G., Umeda, Y., Hoshide, S., Hoshide, Y., Morinari, M., ... Shimada, K. (2003). Morning surge in blood pressure as a predictor of silent and clinical cerebrovascular disease in elderly hypertensives: a prospective study. Circulation, 107(10), 1401-1406. 
Mancia, G., Fagard, R., Narkiewicz, K., Redon, J., Zanchetti, A., Böhm, M., ... Wood, D. A. (2013). 2013 ESH/ESC guidelines for the management of arterial hypertension: the Task Force for the Management of Arterial Hypertension of the European Society of Hypertension (ESH) and of the European Society of Cardiology (ESC). European Heart Journal, 34(28), 2159-2219. http://doi.org/10.1093/eurheartj/eht151

Mediano, M. F. F., Paravidino, V., Simão, R., Pontes, F. L., \& Polito, M. D. (2005). Subacute behavior of the blood pressure after power training in controlled hypertensive individuals. Revista Brasileira de Medicina do Esporte, 11(6), 337-340. http://doi.org/10.1590/S151786922005000600006

Medrano, I. C. (2010). Muscular failure training in conditioninig neuromuscular programs. Journal of Human Sport and Exercise, 5(2), 196-213. http://doi.org/10.4100/jhse.2010.52.09

Melo, C. M., Alencar Filho, A. C., Tinucci, T., Mion, D., \& Forjaz, C. L. M. (2006). Postexercise hypotension induced by low-intensity resistance exercise in hypertensive women receiving captopril. Blood Pressure Monitoring, 11(4),

183-189. http://doi.org/10.1097/01.mbp.0000218000.4 2710.91

Moraes, M. R., Bacurau, R. F. P., Ramalho, J. D. S., Reis, F. C. G., Casarini, D. E., Chagas, J. R., ... Araujo, R. C. (2007). Increase in kinins on post-exercise hypotension in normotensive and hypertensive volunteers. Biological Chemistry, 388(5), 533-540. http://doi.org/10.1515/BC.2007.055

Mota, M. R., Pardono, E., Lima, L. C. J., Arsa, G., Bottaro, M., Campbell, C. S. G., \& Simões, H. G. (2009). Effects of treadmill running and resistance exercises on lowering blood pressure during the daily work of hypertensive subjects. Journal of Strength and Conditioning Research, 23(8), 2331-2338. http://doi.org/10.1519/JSC.0b013e3181bac41 8

Oliveira, J., Silva, A., Prazeres, T., Santos, M., Júnior, C. C., \& Ritti-Dias, R. (2013). Reprodutibilidade interavaliadores da identificação da redução da cadência em exercícios de força. Revista Brasileira de Atividade Física \& Saúde, 17(6), 512-518. http://doi.org/10.12820/rbafs.v.17n6p512518

Pescatello, L. S., Franklin, B. A., Fagard, R., Farquhar, W. B., Kelley, G. A., \& Ray, C. A. (2004). American College of Sports Medicine position stand. Exercise and hypertension. Medicine and Science in Sports and Exercise, 36(3), 533-553.

Polito, M. D., \& Farinatti, P. T. V. (2009). The effects of muscle mass and number of sets during resistance exercise on postexercise hypotension. Journal of Strength and Conditioning Research, 23(8), 2351-2357. http://doi.org/10.1519/JSC.0b013e3181bb71a a

Prista, A., Macucule, C. F., Queiroz, A. C. C., Silva, N. D., Cardoso, C. G., Tinucci, T., ... Forjaz, C. L. M. (2013). A bout of resistance exercise following the 2007 AHA guidelines decreases asleep blood pressure in Mozambican men. Journal of Strength and Conditioning Research, 27(3), 786-792. http://doi.org/10.1519/JSC.0b013e31825d97 83

Queiroz, A. C. C., Gagliardi, J. F. L., Forjaz, C. L. M., \& Rezk, C. C. (2009). Clinic and ambulatory blood pressure responses after resistance exercise. Journal of Strength and Conditioning Research, 23(2), 571-578. http://doi.org/10.1519/JSC.0b013e318196b6 37

Robertson, R. J., Goss, F. L., Rutkowski, J., Lenz, B., Dixon, C., Timmer, J., ... Andreacci, J. (2003). Concurrent validation of the OMNI perceived exertion scale for resistance exercise. Medicine and Science in Sports and Exercise, 35(2), 333341.

http://doi.org/10.1249/01.MSS.0000048831.1 5016.2A

Roltsch, M. H., Mendez, T., Wilund, K. R., \& Hagberg, J. M. (2001). Acute resistive exercise does not affect ambulatory blood pressure in young men and women. Medicine and Science in Sports and Exercise, 33(6), 881-886.

Sociedade Brasileira de Cardiologia, Sociedade Brasileira de Hipertensão, \& Sociedade Brasileira de Nefrologia. (2010). [VI Brazilian Guidelines on Hypertension]. Arquivos Brasileiros De Cardiologia, 95(Suppl 1), 1-51. 